\title{
Status Quo Analysis and Countermeasure Research on the Civil Servants'Job Burnout in Hebei Province
}

\author{
Congman Wang ${ }^{1, a}$, Nannan Shan ${ }^{2, b}$ \\ ${ }^{1}$ School of Hebei University of Science and Technology,Shijiazhuang 050000,China; \\ ${ }^{2}$ School of Hebei University of Science and Technology,Shijiazhuang 050000,China \\ acongmanyu@vip.sina.com.cn, b1006026809@qq.com
}

Keywords: Grass-roots civil servants, job burnout, influence factors,intervention policy.

\begin{abstract}
Nowadays, the social competition is becoming fiercer and fiercer, the competition pressures and working pressures of the working group obviously increased. With the increase of pressure in the working group, the occupational groups in all walks have different levels of job burnout,not excepting the civil servants. Grass-roots civil servants are the basic management of the public affairs, which is the direct power of the government functions. Their works are complicated, and a considerable part of people are in the high work pressure environment, physical and mental fatigue, which is harmful to the health and affects the organization efficiency. Therefore, we need to give much attention to the problem of occupational burnout, and explore the reasonable intervention measures to effectively protect the physical and mental health of the grass-roots civil servants, and promote the scientific development and orderly conduct of basic public management.
\end{abstract}

\section{Introduction}

Civil servants at the grassroots who are different from non grass-roots civil servants are engaged in the basic work of public management.They are in charge of all major routes, principles and policies of the state's direct implementation, also are the bridges and the links to contact the people. They are not only the backbone of civil servants ranks, but also the important safeguard to express and realize the people's public rights. The grass-roots civil servants work at the grassroots level, the work internal model, taking heavy working pressure, therefore they are more prone emerging job burnout. At present, China is in a period of social transformation, the job burnout will not only directly affect the development of civil servants, but also make it difficult to improve the government services.

\section{The Concept of Job Burnout}

Job burnout is used to describe a series of negative symptoms in the work ${ }^{[1]}$. The "burnout" was written by American author Greene in his "A Burn-out Case"in 1961 ${ }^{[2]}$. Burnout is usually used to describe the mental fatigue, low mood, and nerve sensitivity and other adverse reactions caused by drug abuse in the clinic. In 1974, Freudenberge published "Staff Burnout"in the Journal of Social Issues and firstly used the term "Job Burnout"[3]. The term used to describe in the medical industry, education industry, service industry and other industries, workers due to every day facing the different problems, different people, and adding the heavy work pressure, repeated things, individual's higher own requirements and so on, thus showing the negative symptoms such as service object cold, the negative work attitude, dispirited spirit.

Many scholars summed up the study results, the high degree of recognition should be Maslacha's social psychological viewpoint. Maslach defined job burnout as an emotional exhaustion, depersonalization or dehumanization and diminished personal ${ }^{[4]}$. Maslach's three-dimensional degree theory model had been widely recognized by many scholars. His MBI scale of the system had proved to have good reliability and validity, which is used in many industries ${ }^{[5]}$. 


\section{Job Burnout Influencing Factors}

Through literature collation and classification, the research on the influence factors of job burnout is generally considered from four aspects: individual level, vocational level, organizational level and social level.

Individual Level. In the past, the study of the individual factors mainly focuses on the characteristics of population variables and individual personality features. Population variable studies characteristics include sex, age, education, job, working age, marital status, etc.. Cordes (1993)indicated that there was a link between demographic variables and job burnout ${ }^{[6]}$.Personal personality characteristics include self esteem, personality traits, emotional intelligence, work values, self-efficacy, and other factors.

Vocational Level. Li Jingping et al. (2012) studied the relationship between job stress and job burnout. He conducted a field study in the civil service group and found that job burnout caused by job stress is gradually formed, which shows that negative emotions are accumulated, and eventually, in the long-term negative pressure is gradually strengthened ${ }^{[7]}$. Gu Hongmei believes that the pressure source is many-sided, work load, role stress, organizational limitations pressure is an important reason to cause the sense of civil servants burnout. Ni Fen believed that the reasons for burnout are all-round, including role conflict and role ambiguity of civil servants, lacking participation in the work, sufficient stimulating measures and other reasons ${ }^{[8]}$.

Organizational Level. Jing Huaibin found that the leading pattern of civil servants organization will influence the internal interpersonal relations of unit inside the influence of and increase the individual's pressure feeling. If this situation can not be resolved, it will gradually develop job burnout; Zhang Peng (2008) found that the rationality of organization structure is an important aspect $^{[9]}$. Organizational justice is a fair perception of the individual in the context of the organization, employees are often based on their own feelings to make a judgment on the level of organization. Zhou $\mathrm{Ju}$ (2007) pointed out that the organization must be from the performance assessment and supervision mechanism two aspects to achieve fair ${ }^{[10]}$. Bao Xingrong (2010) pointed out that the cause of civil servants job burnout is more. On the specific conditions of the country, the bad ecology of administrative workplace is one of the more important reason ${ }^{[11]}$.

Social Level. Scholars' study in the social level is divided into two categories: social environment and social support. Some aspects of the social environment will have an impact on the individual's job burnout, such as social reform, rapid economic development, etc.. These factors will increase the sense of pressure and competition among practitioners in a certain degree, thus becoming a reason for increasing the sense of burnout. Social support usually refers to all aspects of society, including the spiritual or material help from parents, relatives, friends, etc. ${ }^{[12] .}$ Wang Fang and $\mathrm{Xu}$ Yan discussed the influence factors of job burnout, and thought that good social support had a positive effect on the individual, so as to ease the sense of burnout.

Based on the existing research results and the special characteristics of the research subject. The influence factors of job burnout, which includes the development of career, the system environment, the work load, the personal psychological quality, the interpersonal relationship and the role cognition were determined.

\section{The Job Burnout Status Quo Analysis of Grass-roots Civil Servants in Hebei Province}

This paper selects Chengde Xingtai, Shijiazhuang, Baoding four cities' partial grassroots civil servants from different regions and different units as the survey object to obtain the first-hand information. 729 questionnaires were distributed, 671 were valid. Basic civil servants have some similarities, so it can use these samples to represent the actual situation in Hebei province.

Sample Description.

Collecting the valid questionnaires data and summing the basic information of effective sample, as shown in table 1: 
Table1 Basic data statistics of effective sample

\begin{tabular}{|c|c|c|c|}
\hline Population variable & Characteristic variable & Number of people & Percentage \\
\hline \multirow{2}{*}{ Sex } & Male & 443 & $66 \%$ \\
\hline & Female & 228 & $34 \%$ \\
\hline \multirow{5}{*}{ Age } & 25 years old or below & 52 & $7.7 \%$ \\
\hline & 26 - 35 years old & 253 & $37.7 \%$ \\
\hline & $36-45$ years old & 265 & $39.5 \%$ \\
\hline & $46-55$ years old & 95 & $14.2 \%$ \\
\hline & 56 years old or above & 6 & $0.9 \%$ \\
\hline \multirow{3}{*}{ Marital status } & married & 582 & $86.7 \%$ \\
\hline & Single & 87 & $13 \%$ \\
\hline & divorced or widowed & 2 & $0.3 \%$ \\
\hline \multirow{4}{*}{ Education } & under Junior college & 42 & $6.3 \%$ \\
\hline & junior college education & 188 & $28 \%$ \\
\hline & undergraduate & 419 & $62.4 \%$ \\
\hline & master or above & 22 & $3.3 \%$ \\
\hline \multirow{5}{*}{ Work tenure } & 5 years or below & 148 & $22 \%$ \\
\hline & 6-10 years & 152 & $23 \%$ \\
\hline & $11-15$ years & 121 & $18 \%$ \\
\hline & 16-20 years & 135 & $20 \%$ \\
\hline & 21years or above & 115 & $17 \%$ \\
\hline \multirow{3}{*}{ Position } & ordinary staff & 512 & $76.3 \%$ \\
\hline & deputy chief & 112 & $16.7 \%$ \\
\hline & head section & 47 & $7 \%$ \\
\hline
\end{tabular}

\section{A Statistical Analysis of the Three Dimensions' Frequency and Frequency About the Job Burnout Questionnaire.}

The score shown in Table 2 is the average score of each sample in each dimension and the average score of the scale, which is used to judge the degree of burnout of the civil servants.

As shown in table,the moderate and mild have a higher percentage. In the emotional exhaustion dimension, it shows that the low emotional exhaustion of the civil servants account for the majority. In the dimension of depersonalization, $79.88 \%$ of the surveyed civil servants were mild burnout. In terms of low sense of achievement, it is not difficult to see that the low sense of achievement is the highest level of burnout, which shows a considerable part of the grass-roots civil servants in the work can not be effective in solving the problem, lacking confidence in the future.This problem should be given enough attention.

Table 2 Statistics of occupation tiredness three-dimensional frequency frequency

\begin{tabular}{cccc}
\hline Statistics Contents & Scores & Sample numbers & Effective Percentage \\
\hline \multirow{2}{*}{ Emotional } & $0-2$ (mild) & 437 & $65.13 \%$ \\
exhaustion & $2-3.5$ (moderate) & 203 & $30.25 \%$ \\
& $3.5-5$ (severe) & 31 & $4.62 \%$ \\
Depersonalization & $0-2$ (mild) & 536 & $79.88 \%$ \\
& $2-3.5$ (moderate) & 120 & $17.88 \%$ \\
Sense of low & $0-5$ (severe) & 15 & $2.24 \%$ \\
achievement & $2-3.5$ (moderate) & 161 & $23.99 \%$ \\
& $3.5-5$ (severe) & 398 & $59.31 \%$ \\
Job burnout & $0-2$ (mild) & 321 & $16.69 \%$ \\
& $2-3.5$ (moderate) & 337 & $47.84 \%$ \\
& $3.5-5$ (severe) & 13 & $50.22 \%$ \\
\hline
\end{tabular}




\section{Descriptive Statistical Analysis of the Influencing Factors.}

From the table 3, the data can be known, the mean of the career prospects,system environment and work load is upper than others, which mean these three dimensions are also more concerned about, and servants' pressure from these aspects is also more obvious.

Table 3 The mean ranking of influence factors

\begin{tabular}{cccc}
\hline Influence Factors & $\mathrm{N}$ & Mean & Standard Deviation \\
\hline Career prospects & 671 & 3.0629 & 0.9553 \\
Institutional & 671 & 2.8432 & 0.8430 \\
environment & 671 & 2.6531 & 0.8514 \\
$\quad$ Work load & 671 & 1.8169 & 0.5403 \\
$\begin{array}{c}\text { Personal } \\
\text { psychological quality }\end{array}$ & & 1.9436 & 0.5573 \\
$\begin{array}{c}\text { Interpersonal } \\
\text { relationship }\end{array}$ & 671 & 2.3471 & 0.8011 \\
Role cognition & 671 & 6 & $0.50 \mathrm{Jurn}$ \\
\hline
\end{tabular}

Correlation Between the Factors of Job Burnout and the Dimensions of Job Burnout

Correlation between the career prospects and job burnout dimensions

This part is to analyze the correlation between the various dimensions of job burnout and career prospects. The results follow in table 4 . And it shows that there is a positive correlation between the three dimensions of job burnout and career prospects.

Table 4 The correlation analysis of job prospects dimensionand job burnout

\begin{tabular}{ccccc}
\hline & & $\begin{array}{c}\text { Emotional } \\
\text { exhaustion }\end{array}$ & Depersonalization & $\begin{array}{c}\text { Sense of low } \\
\text { achievement }\end{array}$ \\
\hline \multirow{2}{*}{ Career } & $\begin{array}{c}\text { Pearson relativity } \\
\text { significance } \\
\text { prospects }\end{array}$ & $.384^{* *}$ & $.451^{* *}$ & $.332^{* *}$ \\
& $\begin{array}{c}\text { (bilateral) } \\
\mathrm{N}\end{array}$ & .000 & .000 & .000 \\
\hline
\end{tabular}

Correlation between the institutional environment and job burnout dimensions

This part is about the relationship between the institutional environment and job burnout. The analysis results are as follows as table 5:

Table 5 The correlation analysis of the system environment and job burnout dimensions

\begin{tabular}{ccccc}
\hline & & $\begin{array}{c}\text { Emotional } \\
\text { exhaustion }\end{array}$ & Depersonalization & $\begin{array}{c}\text { Sense of low } \\
\text { achievement }\end{array}$ \\
\hline \multirow{2}{*}{ system } & $\begin{array}{c}\text { Pearson relativity } \\
\text { significance } \\
\text { environment }\end{array}$ & $.133^{*}$ & $.188^{*}$ & $.206^{*}$ \\
& $\begin{array}{c}\text { (bilateral) } \\
\mathrm{N}\end{array}$ & .016 & .026 & .015 \\
& 671 & 671 & 671 \\
\hline
\end{tabular}

The results indicate that the system environment and the three dimensions of job burnout are showing a significant correlation.

Correlation between the work load and job burnout dimensions

Table 6 The correlation analysis of the work load and job burnout dimensions

\begin{tabular}{ccccc}
\hline & & $\begin{array}{c}\text { Emotional } \\
\text { exhaustion }\end{array}$ & Depersonalization & $\begin{array}{c}\text { Sense of low } \\
\text { achievement }\end{array}$ \\
\hline Work load & $\begin{array}{c}\text { Pearson relativity } \\
\text { significance } \\
\text { (bilateral) }\end{array}$ & $.608^{*}$ & $.352^{*}$ & .067 \\
$\mathrm{~N}$ & .026 & .016 & .429 \\
& 671 & 671 & 671 \\
\hline
\end{tabular}

The analysis results are as follows: (1)the work load is significantly related to the emotional exhaustion and the personality dimensions. (2) The correlation coefficient between the work load and the low dimension of achievement is $0.067, \mathrm{P}=0.429$, which is not significant. 
Correlation between individual psychological quality and the job burnout dimensions

The results of the analysis are shown in table 7:

Table 7 The correlation analysis of the personal psychological quality and job burnout dimensions

\begin{tabular}{ccccc}
\hline & & $\begin{array}{c}\text { Emotional } \\
\text { exhaustion }\end{array}$ & Depersonalization & $\begin{array}{c}\text { Sense of low } \\
\text { achievement }\end{array}$ \\
\hline $\begin{array}{c}\text { Personal } \\
\text { psychological } \\
\text { quality }\end{array}$ & $\begin{array}{c}\text { Pearson relativity } \\
\text { significance } \\
\text { (bilateral) }\end{array}$ & $.247^{*}$ & $.181^{*}$ & .051 \\
$\mathrm{~N}$ & .029. & .039 & .549 \\
\hline
\end{tabular}

The results show that: (1) There are significant correlations between individual psychological quality and both. (2)The correlation coefficient between the individual psychological quality and the low achievement sense is more than 0.05 , which indicates that the relativity between the individual psychological quality and the low achievement sense are not significant.

Correlation between interpersonal relationship and job burnout dimensions

Table 8 The correlation analysis of the interpersonal relationship and job burnout dimensions

\begin{tabular}{ccccc}
\hline & & $\begin{array}{c}\text { Emotional } \\
\text { exhaustion }\end{array}$ & Depersonalization & $\begin{array}{c}\text { Sense of low } \\
\text { achievement }\end{array}$ \\
\hline \multirow{2}{*}{$\begin{array}{c}\text { Interpersonal } \\
\text { relationship }\end{array}$} & $\begin{array}{c}\text { Pearson relativity } \\
\text { significance }\end{array}$ & .021 & $.263^{*}$. & $0.325^{*}$. \\
& $\begin{array}{c}\text { (bilateral) } \\
\mathrm{N}\end{array}$ & .979 & .017 & .021 \\
\hline
\end{tabular}

From table 8 , we can see that the correlation coefficient is more than 0.05 , which indicates that the institutional environment is not significantly related to emotional exhaustion. And the interpersonal relationship was significantly related to the two dimensions of personality and achievement, and it had a forecast function.

Correlation between role cognition and job burnout dimensions

Table 9 The correlation analysis of the role cognition and job burnout dimensions

\begin{tabular}{ccccc}
\hline & & $\begin{array}{c}\text { Emotional } \\
\text { exhaustion }\end{array}$ & Depersonalization & $\begin{array}{c}\text { Sense of low } \\
\text { achievement }\end{array}$ \\
\hline \multirow{2}{*}{ Role } & $\begin{array}{c}\text { Pearson relativity } \\
\text { significance } \\
\text { cognition }\end{array}$ & $.121^{* *}$ & $.176^{* *}$ & .108 \\
& $\begin{array}{c}\text { (bilateral) } \\
\mathrm{N}\end{array}$ & .000 & .000 & .206 \\
& 671 & 671 & 671
\end{tabular}

The results showed that: (1) the correlation coefficient of role cognition and emotion exhaustion,depersonalization are 0.121 and 0.176 , and both adjoint probability are more than 0.01 , which indicated that the role of cognitive has a significant predictive effect. (2) the correlation coefficient of role cognition and low achievement sense is 0.108 , the probability is 0.206 , and the two is not significant.

\section{Analytical Results Discussion}

Through the correlation analysis of the job burnout status questionnaire' three dimensions, it shows that the three dimensions are significantly related. They constitute a unified whole, and can be regarded as a state of emotional exhaustion, a combination of depersonalization and low achievement sense. From the descriptive statistical analysis of the influence factors of job burnout,we can be seen that the three aspects including the career prospects, the institutional environment, the work load of bring them more pressure, the other three factors ranking is role cognition, interpersonal relationship, personal psychological quality. In general, the grass-roots civil servants in Hebei province are a general phenomenon of job burnout. Although the overall level of burnout is not high, it still needs to pay attention to. 


\section{Countermeasures and Suggestions for Alleviating the Job Burnout of Civil Servants in Hebei Province}

Career Prospects. The government's efforts are an important force to alleviate this problem. It is necessary to actively improve the promotion of civil servants, and regulate the promotion system of grass-roots civil servants in Hebei Province, to make it more scientific and democratic $^{[13]}$.Government should seek the reasonable promotion channels, appropriately slow down the speed of promotion, so that the capable grass-roots civil servants can have access to the management team to avoid some of the irregularities in the promotion. Organization in this regard should also provide supports.In the normal work, trying to arrange more learning opportunities for the grass-roots civil servants, increasing their experience and skills. Organization should also provide more development space for the grassroots civil servants to give full play to their personal ability.As a grass-roots civil servant, their own efforts should be made. They must see their own work properly, to lower their expectations appropriately, to treat their own future objectively, and to develop practical personal career planning.

Institutional Environment. The system of civil servants in our country has been relatively strict, which result in lacking autonomy of the grass-roots civil servants. And very few can participate in their own opinions and suggestions.In order to solve this problem, the government should promote the implementation of democratic management to make the civil servants integrate organizational goals and personal goals in the process, to improve the organization's belongingness, so that the civil servants can participate in the core of the organizational activities, give full play to their enthusiasm, improve work efficiency and job satisfaction, so as to solve the problem of job burnout.In the performance evaluation, the government should establish a sound, scientific and reasonable performance evaluation system. The assessment process should be strictly implemented, detailed assessment indicators, made clear assessment standards, opened the process of public assessment, to ensure the assessment results fair and equitable. Finally, the assessing results must be seriously implemented.

Work Load. The organization should actively seek ways to reduce the work burden. Make efforts from the following aspects: first, the organization should reasonably arrange the internal staff, through increasing staffing, reasonable transferring or seconding staff to alleviate the heavy temporary task and adjust the tasks allocation; Second, we can give full play to the role of e-government in the office.Through making full use of some information technology to improve work efficiency, which in a certain sense can save time and human resources; Third, grass-roots civil servants must establish the correct value concept and recognize the exercise of own ability to work in the grass-roots work.It's the process of experience accumulation for their future work.

Personal Psychological Quality. For the grass-roots civil servants in the presence of individual psychological quality of the situation, the organization should be in the right place to carry out psychological education work, or to their psychological counseling. In the normal work life, the organization should carry out the mental health training activity in the right time, develop their good professional psychological quality. On the other hand, when faced with the problem of job burnout can not be overcome, we can seek help from psychological counseling agencies. This can also be regarded as a good way to ease the psychological pressure to prevent the problem of job burnout.

In addition,the ordinary people should take a correct view of the civil servants groups, realize that the civil servants are also ordinary people, and their ability is limited. We should keep their due respect, actively cooperate with and support their work.

Interpersonal Relationship. On the one hand, The government departments can actively promote the democratization of the organization's decision-making, encourage more grass-roots civil servants to participate actively in the organization and management. So that they can put forward their views to strengthen the work exchange and eliminate unnecessary conflicts and barriers in the work. On the other hand,it would promote the leadership and the upper and lower levels of communication. Also we could hold some amateur activities to strengthen the feelings between colleagues.

In the daily work and life, grass-roots civil servants must actively learn and improve 
communication skills. Trying to avoid interpersonal friction and conflict, failing to learn empathy, and standing in each other viewpoint to the problem. In addition, when someone encounters the problem of interpersonal conflict, it would actively seek help, and face the pressure to prevent burnout. In daily work, to strengthen communication with colleagues, mutual help, learn the advantages of others, learn from each other, help to relieve the individual in at the beginning of the job burnout of boredom and depression.

Role Cognition. Role cognition problems are mainly about two aspects: role conflict and role ambiguity. When some have different perceptions or expectations of others' role, then there is a role conflict.Popular speaking, the individual receives different instructions on the work, and he or she doesn't know who it should listen to. Role ambiguity is the lack of clear understanding and recognition of the given expectations and tasks. For the role cognitive problems, we should try to do the following two points.First, the organization should be based on the work nature of the grass-roots civil servants of different positions to formulate scientific, reasonable, detailed analysis of the work, and the clear statement of work. The job duties and tasks of the grass-roots civil servants in the form of a written document is clear.The later work's distribution should be strictly in accordance with the job description and job responsibilities. So as to avoid the occurrence of the fuzzy, which could increase the enthusiasm of the grass-roots civil servants. Second, in addition to clear task allocation, but also we need to supervise and assess their task completion, as far as possible to reduce the role of fuzzy phenomenon.

\section{References}

[1] Zeng Xioali, The reaserch of relationship between coping way and job burnout of civil servants,Chongqing,Southwest University,2010

[2] Zhang Hongyu, An analysis of the university teachers' job burnout status and countermeasures, Tianjin Agricultural University,3 (2009) 30-35

[3] H. J. FREUDENBERGER, Staff Burn-Out.Journal of Social Issues,3.1974

[4] C. MASLACH, A MULTIDIMENSIONAL. Theory of Burnout. C. L. COOPER. Theory of Organizational Stress. London: Oxford University Press, (2001) 68-85

[5] C. MASLACH, S. E.JACKSON, M. B: burnout inventory. CA: Consulting Psychologists Press, 1981

[6] C.L. COEDES, T.W. DOUGHERTY, A Review and Integration of Research On Job Burnout. Academy of Management Review, 18,(1993) 621-656

[7] Li Jingping,Lu Yang,Li Jiaying.The influential relationship between working pressure and job burnout:a survey on Ydistricy of X city.Journal of Northwest University, 42,2 (2012) 144-150

[8] Ni Fen.Causes and Countermeasures of the civil servants' job burnout, Journal of The Party School of Guizhou Provincial Committee of the C.P.C,4,(2009) 53-55

[9] Gu Hongmei. Official position and job burnout,Law and Economy,3, (2006) 65-66

[10] Zhou Ju. Civil servants' job burnout and stress management,Discovery3,(2007) 67-71

[11] Bao Xingrong.Analysis on the phenomenon of job burnout of civil servants in China and the workplace eco-operation.Journal of Sichuan Administration College,4,(2010) 20-24

[12] Zhou Li. Social support research in the process of students to achieve career decision making self-efficacy - Based on Sichuan University of Science\&Engineering. Southwest University,2010

[13] Du Xingyag, Tian Jin.The study of civil servants career development path based on competence,Chinese Public Administration, 11, (2011) 105-109 